\title{
Os conceitos de Florence Nightingale em tempos de pandemia da COVID-19 retratados em história em quadrinhos: relato de experiência ${ }^{a}$
}

\author{
Florence Nightingale's concepts in times of COVID-19 pandemic portrayed in comics: an experience report \\ Los conceptos de Florence Nightingale en tiempos de pandemia COVID-19 retratados en cómics: relato \\ de experiencia
}

Lucas Eduardo Mello Barboza ${ }^{1}$ (D) Isaque Souza da Silveira ${ }^{1}$ (D)

Paula Carvalho Leite ${ }^{1}$ (D) Marialda Moreira Christoffel ${ }^{1,2}$ (1) Ana Leticia Monteiro Gomes ${ }^{2}$ (B) Tania Vignuda de Souza² (1) Gláucia Cristina Lima da Silva² (B)

1. Universidade Federal do Rio de Janeiro. Macaé, RJ, Brasil.

2. Universidade Federal do Rio de Janeiro, Escola de Enfermagem Anna Nery. Rio de Janeiro, RJ, Brasil.
Autor correspondente:

Ana Leticia Monteiro Gomes.

E-mail: analeticiagomes88@gmail.com.

Recebido em 28/05/2020.

Aprovado em 12/09/2020

\section{RESUMO}

Objetivo: Descrever a experiência do processo de elaboração de uma história em quadrinhos acerca das medidas de prevenção para o combate ao novo coronavírus a partir do legado de Florence Nightingale e da Teoria Ambientalista. Método: Trata-se de um relato de experiência de uma ação extensionista universitária acerca do processo de elaboração de uma história em quadrinhos que traz os conceitos da teoria ambientalista de Florence Nightingale no combate ao novo coronavírus. Resultados: A partir da técnica do brainstorming, surgiu a ideia da história em quadrinhos e foram criados três personagens: Florence Nightingale, Super Sabão e Luiza. Foram seguidas as etapas: criação do roteiro e dos personagens e transferência do desenho manual para programas de digitalização. O material elaborado passou por três revisões: a dos alunos de enfermagem; do docente responsável pela elaboração do material e; do grupo de docentes cuja finalidade foi avaliar os materiais produzidos nas atividades de extensão acerca do tema COVID-19. Conclusão e implicações para prática: A experiência na construção de material didático tipo história em quadrinhos foi um desafio para os estudantes e docentes. Destaca-se a oportunidade da descoberta de novos recursos pedagógicos e produção de material tecnológico em tempos de distanciamento social.

Palavras-chave: História em Quadrinhos; Enfermagem; Saúde da criança; Infecções por Coronavírus; Educação em Saúde.

\begin{abstract}
Objective: To describe the experience of the process of elaboration of a comic about prevention measures to combat the new coronavirus from the legacy of Florence Nightingale and the Environmental Theory. Method: It is an experience report of a university extension action about the process of elaboration of a graphic novel that brings the concepts of Florence Nightingale's environmental theory in the fight against the new coronavirus. Results: From the brainstorming technique, the comic idea came up and three characters were created: Florence Nightingale, Super Sabão (Super Soap, in free translation), and Luiza. These stages were followed: creation of the script and characters and transfer of the manual drawing to digitization programs. The material produced underwent three revisions: that of nursing students; of the teacher responsible for preparing the material and; of the group of teachers whose purpose was to evaluate the materials produced in extension activities on the theme COVID-19. Conclusion and implications for practice: The experience in the construction of didactic material such as a graphic novel was a challenge for students and teachers. Stands out the opportunity to discover new pedagogical resources and the production of technological material in times of social distancing.
\end{abstract}

Keywords: Comic; Nursing; Child health; Coronavirus infections; Health education.

\section{RESUMEN}

Objetivo: Describir la experiencia del proceso de preparación de una historieta (cómics) sobre las medidas preventivas para el combate al nuevo coronavirus a partir del legado de Florence Nightingale y de la Teoría Ambientalista. Método: Relato de experiencia de una acción de extensión universitaria acerca del proceso de elaboración de un cómic que trae los conceptos de la Teoría Ambientalista de Florence Nightingale en la lucha contra el nuevo coronavirus. Resultados: A partir de la técnica de brainstorming (lluvia de ideas), surgió la idea del cómic y se crearon tres personajes: Florence Nightingale, Súper Jabón y Luiza. Se siguieron los pasos: creación del guion y de los personajes y transferencia del dibujo manual a programas de digitalización. El material producido se sometió a tres revisiones: por alumnos de enfermería; docente responsable de preparar el material y; del grupo de docentes cuyo propósito era evaluar los materiales producidos en actividades de extensión sobre el tema COVID-19. Conclusión e implicaciones para la práctica: La experiencia en la construcción de material didáctico como los cómics fue un desafío para estudiantes y profesores. Se destaca la oportunidad de descubierta de nuevos recursos pedagógicos y la producción de material tecnológico en tiempos de aislamiento social.

Palabras clave: Historieta; Enfermería; Salud de los niños; Infecciones por coronavirus; Educación para la Salud. 


\section{INTRODUÇÃO}

O ano de 2020 marca grandes acontecimentos para a enfermagem mundial e brasileira, tanto por ser este considerado o ano internacional dos profissionais de enfermagem e obstetrícia pela Organização Pan-Americana da Saúde (OPAS) e pela Organização Mundial da Saúde (OMS), ${ }^{1}$ como pela celebração do bicentenário do nascimento de Florence Nightingale.

Nascida em 1820 em Florença, na Itália, Florence Nightingale é considerada a fundadora da Enfermagem Moderna em todo o mundo, obtendo projeção maior a partir de sua participação como voluntária na Guerra da Criméia (1853-1856) no cuidado aos soldados. O reconhecimento mundial de Nightingale veio desse período, quando ela estabeleceu protocolos de abordagem que colaboraram para a redução da mortalidade dos soldados britânicos. Pioneira em um contexto em que a mulher não podia estudar ou trabalhar, Florence foi consagrada como a "Dama da Lâmpada"² por sua valorosa atuação.

No Brasil, o Sistema Nightingale representa uma inestimável contribuição à Enfermagem. Na década de 1920, ocorreu a fundação da primeira Escola no Modelo Nightingale, a então Escola de Enfermeiras do Departamento Nacional de Saúde Pública, criada em 1923. Atualmente, a instituição existe com o nome de Escola de Enfermagem Anna Nery. ${ }^{3}$

Apesar dessas referências para a história da Enfermagem, o ano de 2020 tem sido um grande desafio para esses profissionais quanto à atuação e implementação das medidas de proteção e de combate à pandemia do novo coronavírus. Com a denominação de "novo" por até então nunca ter sido encontrado em seres humanos, sabe-se agora que esse vírus provoca nas pessoas a Síndrome Respiratória Aguda Grave, denominada SARS-CoV-2 (Severe Acute Repiratory Syndrome Coronavirus 2), também denominada COVID-19. Esse vírus pode se propagar de pessoa para pessoa (transmissão direta) por meio de perdigotos lançados no momento da fala, espirro e tosse, ou indiretamente por meio das mãos, que entram em contato com as superfícies contaminadas (fômites) e podem transportar o vírus de um local para o outro. Até o presente momento, não existe tratamento nem vacina específicos para a infecção causada pelo novo coronavírus.

Neste sentido, destaca-se a importância da teoria ambientalista de Florence Nightingale em tempos de pandemia COVID-19, que retoma os cuidados relacionados à higiene dos ambientes, do corpo e da água, além de priorizar a ventilação natural, roupas adequadas, entre outros.

Com o avanço da pandemia, a grande preocupação da OMS está nos países em desenvolvimento, predominantemente localizados na América Latina, África e Oriente Médio, locais onde os serviços de saúde estão menos preparados para o enfrentamento da pandemia por diversos motivos, dentre os quais a escassez de profissionais de saúde, especialmente os da enfermagem. Dados apresentados pela OMS indicam que, para atingir a meta da cobertura universal de saúde até 2030, seriam necessários mais de 9 milhões de enfermeiras(os) e parteiras no mundo. Atualmente, somente para as Américas estas categorias profissionais estão dentro dos 800 mil profissionais de saúde destacados pela OPAS. ${ }^{1}$

Os profissionais de enfermagem possuem como um dos seus papéis fundamentais a disseminação do conhecimento para a população por meio de educação em saúde, através do diálogo com a comunidade acerca das questões da prevenção da contaminação e infecção pela COVID-19, buscando assim retardar o pico epidemiológico da doença.

Dentre as medidas fundamentais no combate a COVID-19, destacam-se as práticas de higiene pessoal, como a lavagem frequente das mãos por no mínimo 20 a 30 segundos, limpeza rigorosa de superfícies inanimadas e do ambiente, bem como, etiqueta respiratória quando apresentar síndrome respiratória, manutenção de ambientes arejados, distanciamento social, dentre outros. ${ }^{4}$

Florence Nightingale deixou um legado que está mais vivo do que nunca, nesse contexto da pandemia da COVID-19 que o mundo enfrenta. Tal legado vai além das práticas de higiene, e engloba a utilização da epidemiologia com a estatística e gráficos para mostrar e melhorar a interpretação dos dados. Por meio de sua Teoria Ambientalista, é possível verificar o quanto essa teoria causa impacto na atualidade. ${ }^{2,5}$

No livro "Notas sobre Enfermagem", de 1860, Florence Nightingale escreveu que "toda enfermeira deve ter o cuidado de lavar suas mãos muito frequentemente ao longo do dia. Se lavar o rosto, também, ainda melhor". Dizia ainda sobre a necessidade de manter janelas abertas para ventilação do ar, tapetes esfregados e ralos limpos. Tais princípios de práticas de higiene ajudaram a transformar os conceitos de saúde pública. Florence valorizou a importância de ambientes benéficos para a saúde mental e física; acreditava que pacientes tinham menos chances de melhorar se ficassem deprimidos ou desesperados. ${ }^{2}$

Para Florence Nightingale, a preparação do ambiente deve assegurar as condições sanitárias das moradias, sendo estas: ar puro, água pura, esgoto eficiente, limpeza e iluminação. Além do princípio de moradias saudáveis, também deveriam ser observados o controle de atividades do cotidiano, alimentação, cama e roupas de cama, conversas sobre esperanças e conselhos, observação do doente, cuidado com o cuidador e alfabetização científica em saúde dos cuidadores baseados na Teoria Ambientalista de Florence Nightingale. Tais princípios sustentam as práticas de enfermagem e são relevantes na luta contra a atual infecção pelo novo coronavírus (COVID-19)..$^{2,5}$

Diante dos conhecimentos herdados de Florence Nightingale e o contexto da pandemia da COVID-19, vimos a oportunidade de congregar tais conhecimentos na produção de material educativo pela extensão universitária, como um processo interdisciplinar educativo, cultural, científico e político, que promovesse a interação transformadora entre universidade e sociedade. Esta congregação ocorreu por meio de uma história em quadrinhos, considerada um produto de cultura de massa, presente no cotidiano de crianças, jovens e adultos. ${ }^{6}$ Atuando com estudantes em projetos de extensão, vimos a necessidade de disseminar informações, orientações e cuidados para prevenir 
e evitar a propagação da COVID-19 em crianças e os familiares que compartilham do mesmo domicílio.

No Brasil, o diálogo entre quadrinhos e saúde surgiu em meados de 1920 com Monteiro Lobato, que escreveu Jeca Tatu - A Ressurreição. O conto, mais conhecido como Jeca Tatuzinho, serviu de inspiração para uma história em quadrinhos bastante popular, que foi divulgada em todo país através do Almanaque do Biotônico Fontoura. ${ }^{7} \mathrm{Na}$ educação, a História em Quadrinhos (HQ) tem seus primeiros registros a partir dos anos 1970, com a inserção dos quadrinhos nos livros didáticos. Existem vários autores e estilos dessa forma de comunicação, dentre eles, podemos destacar o autor Ziraldo Alves Pinto, que criou "O menino Maluquinho". Em sua obra, Ziraldo trata de assuntos diversos, como valores, a importância da educação e do esporte para as crianças. ${ }^{8}$

Recentemente, o famoso cartunista Mauricio de Sousa e os produtores da revista Turma da Monica, que em 1961 criaram o personagem Cascão, conhecido por não gostar de tomar banho, também aderiram ao enfrentamento da COVID-19, quando lançaram uma edição com o personagem lavando as mãos e, assim, transmitindo às crianças uma mensagem positiva e lúdica sobre a importância da higiene pessoal. ${ }^{9}$

A $\mathrm{HQ}$ produz características de linguagem únicas, com a junção do visual com textual, em narrativa leve e breve. É um gênero que consiste em enredos contados em pequenos quadros, por meio de diálogos diretos entre seus personagens, gerando uma espécie de conversação. Sua estrutura é composta por ilustrações e balões, onde estão a fala do personagem, seu pensamento, ou onomatopeias, que são palavras que imitam a voz de animais ou ruídos de objetos. Como exemplo de onomatopeias temos: BUUM!!! (explosão), TOC-TOC! (batendo à porta). ${ }^{10}$

O presente estudo tem como objetivo descrever a experiência do processo de elaboração de uma história em quadrinhos acerca das medidas de prevenção para o combate ao novo coronavírus a partir do legado de Florence Nightingale e da Teoria Ambientalista.

\section{MÉTODO}

Para a preparação desse trabalho, foi utilizada a técnica brainstorming (tempestade de ideias) com estudantes e docentes dos projetos de extensão, em encontros remotos que aconteciam quinzenalmente. A técnica brainstorming foi desenvolvida especificamente para desenvolver a criatividade e a produtividade dos indivíduos durante as sessões de geração de ideias. ${ }^{11}$

A partir desse exercício, surgiu a ideia de criar uma história em quadrinho para crianças e suas famílias com a participação da Florence Nightingale, já que neste ano são comemorados 200 anos do seu nascimento e também o seu legado quanto aos princípios da Teoria Ambientalista, associando esses elementos com a pandemia que estamos vivendo.

Para o levantamento das informações sobre educação em saúde, foi realizada uma revisão bibliográfica na Biblioteca Virtual em Saúde (BVS), em busca de histórias em quadrinho, artigos sobre a Teoria Ambientalista de Florence Nightingale e seus princípios, boletins informativos do Ministério da Saúde e da Organização Mundial de Saúde sobre medidas de prevenção e combate à COVID-19 para revisão bibliográfica.

Após a seleção desse material, foi realizada leitura crítica e discussão com docentes e alunos. Uma $\mathrm{HQ}$ sobre a vida de Florence Nightingale e a profissão da enfermagem foram encontradas, além de um vídeo sobre sua vida em forma de cordel. ${ }^{12,13} \mathrm{Após}$ análise minuciosa, foram desenvolvidas atividades sistematizadas, como a leitura dos artigos, escrita do roteiro pelos estudantes e análise desses roteiros pelos docentes para compreensão e interpretação das condições de produção escrita. Com as reuniões remotas, iniciou-se o processo de criação e adaptação do texto para a linguagem da História em Quadrinho do papel para o ambiente digital. O roteiro final foi analisado pelos docentes e detalhado quanto à situação de interlocução por meio da história em quadrinho, a criação dos personagens e o contexto dos princípios de higiene e ambiente domiciliar de Florence Nightingale associando-os com as medidas de proteção da COVID-19 visando garantir um conhecimento necessário para o processo da produção escrita e criativa.

Para a produção da história em quadrinho, foram realizadas as seguintes etapas: roteiro da história propriamente dita, com a sinopse de toda a história, cenário, personagens e seus perfis; figurino e enquadramento de quadrinhos, respeitando a sua organização quanto ao tempo de ação; número de páginas; linguagem gráfica; arte sequencial da narrativa; e a ferramenta digital.

Dois alunos inseridos no Projeto "Segurança do recém-nascido e criança em diferentes contextos", com habilidades de desenho e web design, aceitaram o desafio proposto pela coordenadora do projeto. $O$ processo de elaboração do material educativo se deu no período de março a abril de 2020, com reuniões remotas entre as cidades de Macaé, Cabo Frio e Rio de Janeiro.

Após a finalização, a história em quadrinho digital (HQD) foi encaminhada para dois professores de enfermagem que atuam na extensão universitária, para que pudessem fazer recomendações e após, os ajustes, o material pudesse ser divulgado no repositório da Escola de Enfermagem Anna Nery, no site: https://eean.ufrj.br/index.php/coronavirus

\section{RESULTADOS}

Foram criados três personagens principais: Florence Nightingale, Super Sabão e Luiza. O cenário escolhido foi o ambiente domiciliar, tendo em vista que o distanciamento social através da reclusão em casa é uma das medidas de prevenção para a COVID-19 e, de acordo com os conceitos de Florence Nightingale, é neste ambiente que se dá os principais cuidados à criança, principalmente no que se refere à higiene corporal $\mathrm{e}$ dos espaços da casa, e de ter em geral boa ventilação, itens fundamentais para esses tempos de pandemia.

A primeira versão do roteiro, intitulado "Florence em....as crianças contra a COVID-19" com a criação dos desenhos dos personagens e o cenário do domicílio foram apresentados pelos 
alunos aos docentes. O roteiro da história foi lido e relido com a conotação da linguagem de contação de história dos personagens e suas falas. Após essa leitura e a discussão dialógica entre o grupo de alunos e docentes, foram realizadas várias sugestões quanto à linguagem escrita, coerência da sequência dos diálogos e representações dos balões (espaço onde aparece a fala).

A versão do roteiro 1 sofreu modificações em seu título, sequência das falas e dos personagens. A partir dessas intervenções, os estudantes transferiram a $\mathrm{HQ}$ do papel para o ambiente digital. As narrativas da HQD culminaram na versão 2 do roteiro, intitulado "Florence Nightingale e Super Sabão em... Luiza contra o novo coronavírus" (Quadro 1).

Concomitante à versão escrita do roteiro 1 , houve o processo de criação da arte, dos personagens, cenário, vestimentas e das cenas de cada quadrinho adequado ao texto. $O$ desenho manual foi realizado por um dos alunos com habilidade em desenho. $O$ desenho dos personagens se mostra com detalhes, perspectivas e cores. Para o processo de arte, foi utilizado lápis de cor e hidrocolor, utilizando no desenho tanto as cores primárias como as secundárias.

Em seguida, foram apresentados os personagens principais, discutindo coletivamente os possiveis pontos a melhorar, por exemplo, a visualização dos personagens e as cenas que iriam ser produzidas para, então, estar em sintonia com a história a ser contada. Os personagens da versão 1 e 2 são apresentados na Figura 1.

Na elaboração da primeira versão, intitulada "Florence em...as crianças contra a COVID-19", os alunos já com o roteiro escrito, o cenário e os personagens da Luiza e família, transferiram as imagens do papel para o software Adobe Photoshop CS6, programa adequado para edição de diferentes camadas, onde foi montado o layout das quatro páginas. Nesse programa, foram criadas as células da HQD utilizando as ferramentas que o próprio software oferece. Já os personagens de Florence Nightingale, o Super Sabão e o novo coronavírus foram desenhados à mão, escaneados e importados para o site https://www.storyboardthat. $\mathrm{com} / \mathrm{pt}$.

A estética e o texto foram retratados em figuras simples. Para iniciar o processo de digitalização, as páginas foram diagramadas, coloridas e ajustadas quanto ao enquadramento. Após a confecção, as células foram baixadas individualmente em formato de imagem para o software. Após a finalização dessa primeira versão, que contou com 21 quadrinhos e três páginas, a mesma foi apresentada ao grupo de docentes para a apreciação da HQD.

Após essa primeira versão da HQD, o material sofreu duas revisões quanto ao texto do roteiro devido por conter frases incompletas, ausência de palavras e necessidade de ajustes da sequência dos diálogos nos balões. Além disso, o desenho do planeta Terra não o caracterizava totalmente. As figuras dos personagens, quando transferidas do desenho para a versão digital, não ficaram adequadas, devido à escassez da variedade de mudanças de movimentos e expressões faciais, chegando à conclusão que o software não ajudava nos efeitos dos personagens. Assim, foi necessário rever a estrutura dos desenhos em cada quadrinho e selecionar um novo software para os ajustes da ideia de movimento dos personagens. A Figura 2 apresenta a primeira página da versão roteiro 1 da HQD.

Para a segunda versão da HQD, foi utilizado o programa online "Storyboard That" em sua versão de teste. No Story

Quadro 1. Apresentação das versões 1 e 2 do roteiro da HQ.

\begin{tabular}{|c|c|c|}
\hline Título & Versão roteiro 1 & Versão roteiro 2/final \\
\hline Diálogos da HQ & Florence em...as crianças contra a Covid-19 & $\begin{array}{l}\text { Florence Nightingale e Super Sabão em...Luiza contra o } \\
\text { novo coronavírus }\end{array}$ \\
\hline 01 & $\begin{array}{l}\text { Luiza é uma menina muito alegre e divertida. } \\
\text { Gosta de brincar, assistir televisão e ver seus } \\
\text { amigos da escola. }\end{array}$ & $\begin{array}{l}\text { Luiza é uma menina muito alegre e divertida. Gosta } \\
\text { de brincar com seus amigos, assistir televisão e de ir à } \\
\text { escola. }\end{array}$ \\
\hline \multirow{3}{*}{02} & $\begin{array}{l}\text { Luiza não entendeu muito bem quando seus } \\
\text { pais ocuparam a televisão e começaram a } \\
\text { passar mais tempo em casa. }\end{array}$ & \multirow{3}{*}{$\begin{array}{l}\text { Ela não entendeu muito bem quando seus pais } \\
\text { passaram assistir à televisão e ficar mais tempo em } \\
\text { casa. }\end{array}$} \\
\hline & - Papai? Eu quero assistir desenho! & \\
\hline & $\begin{array}{l}\text { - Luiza, nós precisamos ver o jornal! - } \\
\text { respondeu seu pai, Carlos. Ele parecia... } \\
\text { nervoso? }\end{array}$ & \\
\hline \multirow[b]{2}{*}{03} & $\begin{array}{l}\text { Depois, não entendeu quando teve que parar } \\
\text { de ver seus amigos e deixar de ir à escola. }\end{array}$ & $\begin{array}{l}\text { Ela não entendeu por que deixou de ir à escola e ver } \\
\text { seus amigos }\end{array}$ \\
\hline & - Mamãe, por que não posso visitar o Caio? & $\begin{array}{l}\text { (sugestão: Por que não posso ir mais à escola? Por } \\
\text { que não posso mais brincar com meus amigos no } \\
\text { parquinho?) }\end{array}$ \\
\hline
\end{tabular}




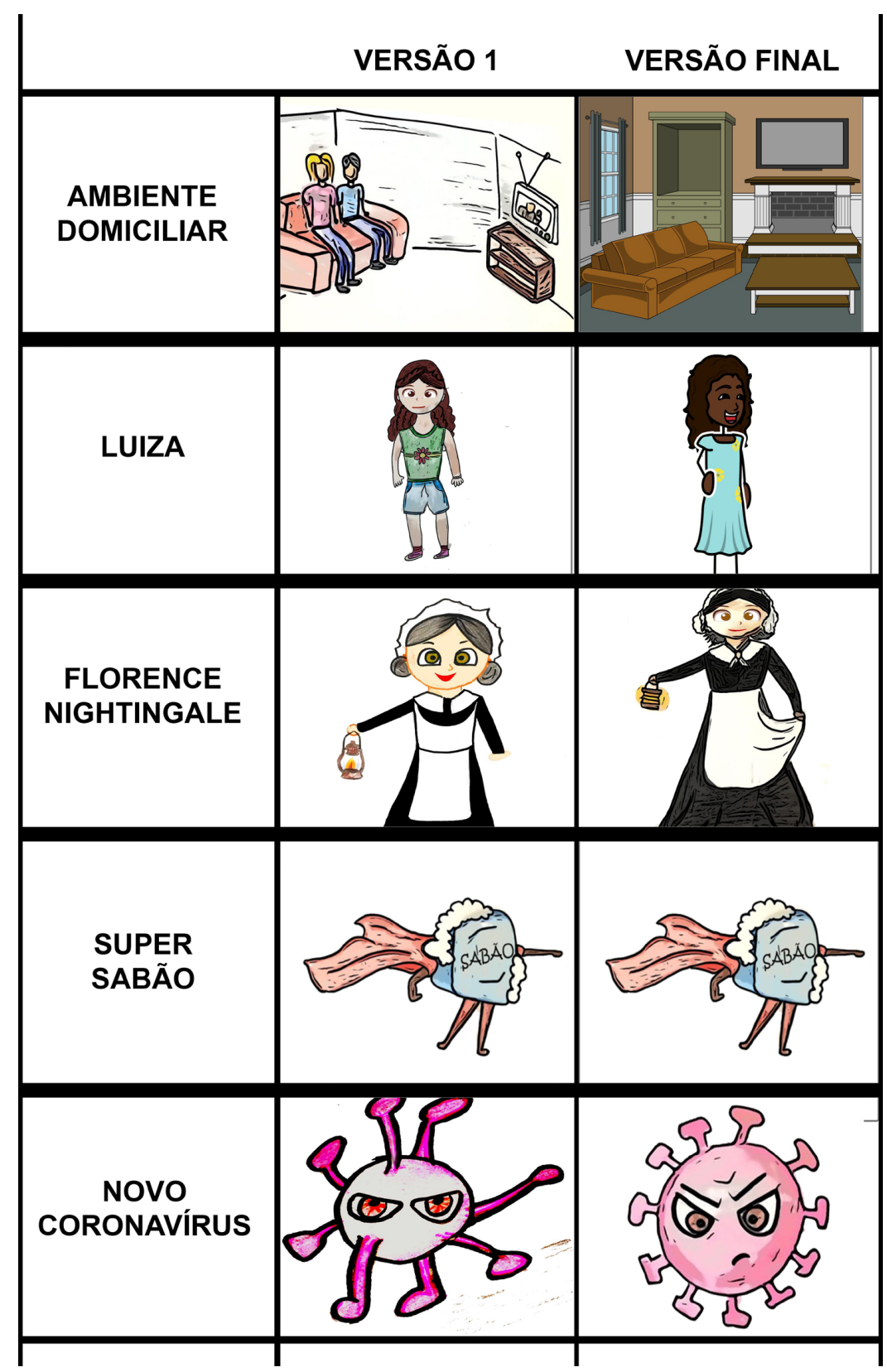

Figura 1. Apresentação dos personagens ainda no processo de criação e as versões dos personagens.

Board, são organizados gráficos tais como uma série de ilustrações ou imagens arranjadas em sequência, com o propósito de pré-visualizar um filme, animação ou gráfico animado, incluindo elementos interativos em website. ${ }^{14}$

A partir das revisões e da avaliação pelo grupo de docentes e alunos, foi realizada a ordenação dos balões narrativos, com ampliação das medidas preventivas no combate ao COVID-19. Também foi modificado o título da versão roteiro 1, intitulado "Florence em... as crianças contra a COVID-19". Para a segunda versão da HQD, o título também foi alterado para "Florence Nightingale e Super Sabão em...Luiza contra o novo coronavírus".

A segunda versão contém basicamente a mesma história, entretanto, a visualização gráfica, cores de fundo dos quadrinhos e a própria personagem Luiza sofreram modificações quanto à estética e visualização. (Figura 3)

A segunda versão contou com 23 quadrinhos e três páginas, além de uma página editorial onde continham informações sobre os autores, sendo a versão final constituída de quatro páginas. A segunda versão foi salva em formato PDF para que o material tivesse uma boa resolução e imagens inalteradas. 
Florence Nightingale em Quadrinhos na COVID-19

Barboza LEM, Silveira IS, Leite PC, Christoffel MM, Gomes ALM, Souza TV, Silva GCL

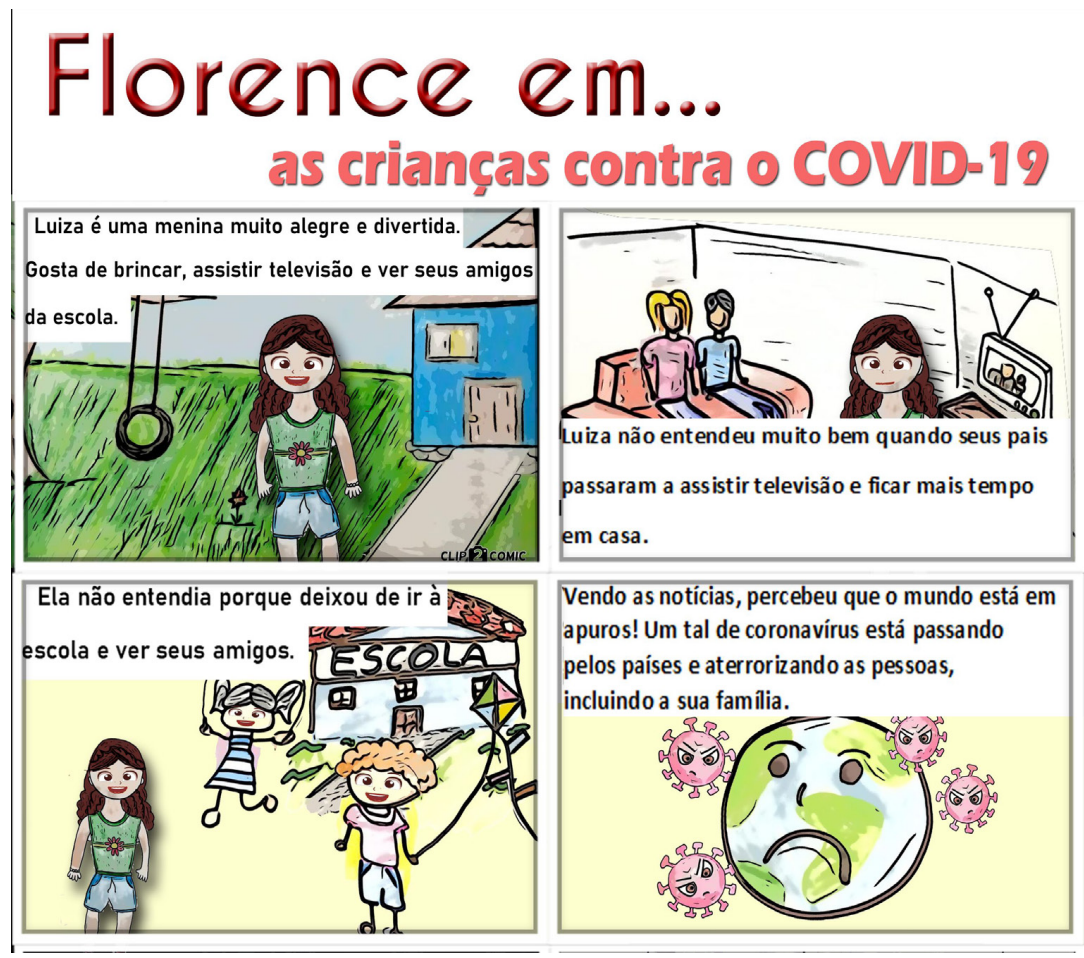

Figura 2. Apresentação da versão roteiro1 da HQD intitulada: “Florence em...as crianças contra a COVID-19".

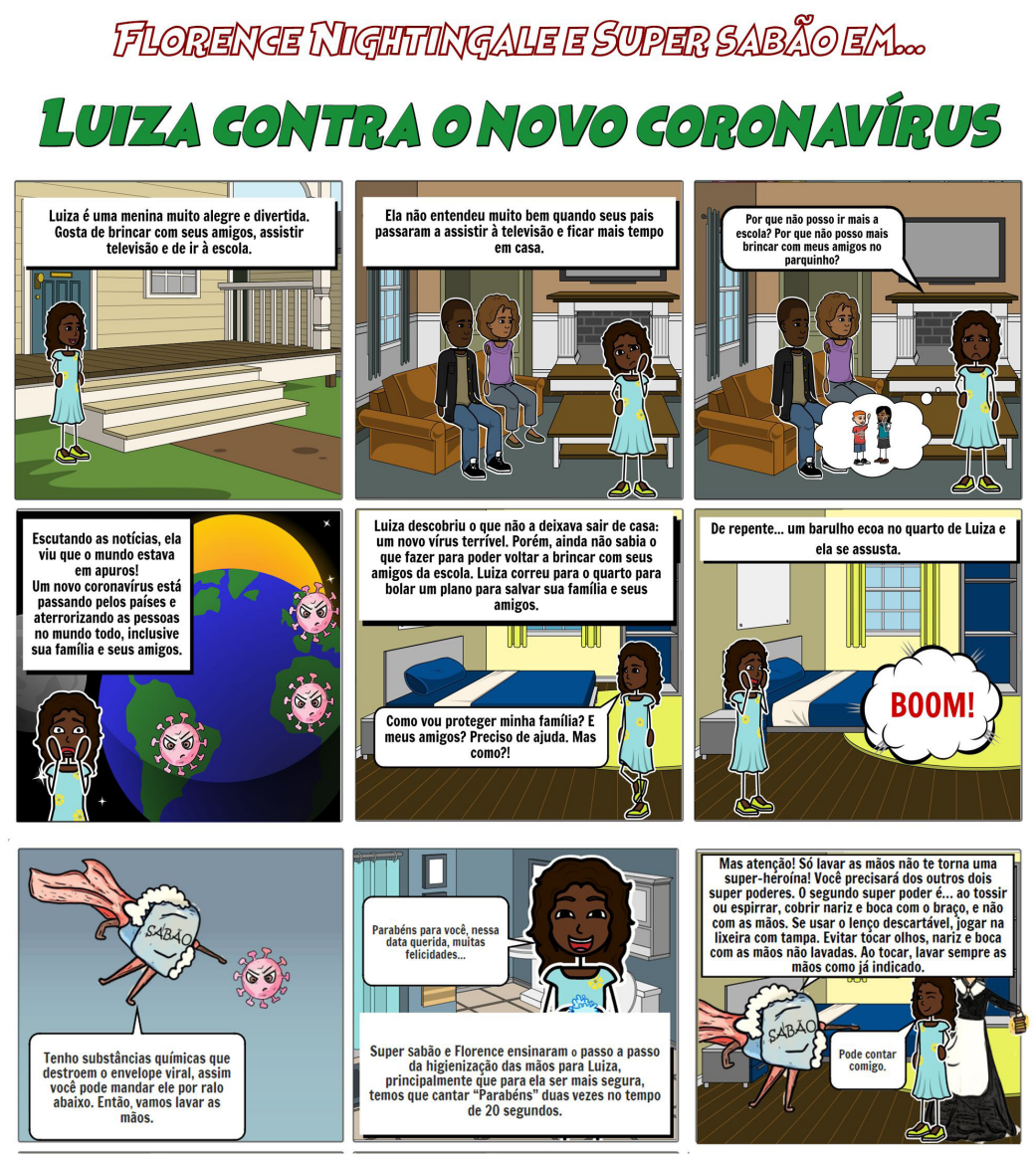

Figura 3. Apresentação da versão final da HQD, intitulada: "Florence Nightingale e Super Sabão em...Luiza contra o novo coronavírus". 


\section{DISCUSSÃO}

O processo de produção da HQD foi voltado para o contexto da Teoria Ambientalista de Florence Nightingale, que tem como foco principal o meio ambiente, levando em consideração as influências deste na saúde do indivíduo, ou seja, as suas defesas naturais são impactadas por um ambiente saudável ou não, destacando-se as crianças, que apesar de sofrerem as mesmas influências do ambiente, são mais suscetíveis a elas, sendo os pequenos acometidos de forma mais rápida e severa. Neste sentido, recomendava-se na história estar em um ambiente arejado, com roupas adequadas ao clima, mantendo a higiene dos espaços da casa, roupas, cama, corpo, entre outros. ${ }^{2}$

$O$ destaque dado aos preceitos desta teoria, justifica-se ao distanciamento social imprimido pela pandemia da SARS-CoV-2/ COVID-19 e ao conhecimento da higienização frequente das mãos, ventilação natural dos ambientes, fuga de ambientes com aglomerações de pessoas e manutenção do lazer/brincadeira das crianças, como recomendações importantes no controle da disseminação da infecção pelo novo coronavírus e o equilíbrio emocional da criança, clamando para mudanças de condutas/ comportamentos quanto à higiene do meio ambiente, que volta à tona com preceitos e ensinamentos propostos por Florence Nightingale na segunda metade do Século XIX e que se mantêm atuais ainda neste século XXI, ano em que se comemora o bicentenário do seu nascimento.

Nesses tempos de pandemia e distanciamento social, conseguir alcançar as crianças e os adolescentes para abordar os cuidados de higiene em uma linguagem acessível e lúdica, ao mesmo tempo que se homenageia esta enfermeira precursora da enfermagem moderna em seu bicentenário de nascimento, a criação do HQD visando atender às questões relacionadas à higiene dos ambientes e principalmente das mãos, levou à personificação do personagem Super Sabão.

Durante a vivência do processo de elaboração e finalização da HQD, foi observado pelos alunos que as principais dificuldades da utilização de tecnologias educativas associadas com tecnologias de informação e comunicação na área da enfermagem da saúde da criança foi um desafio, pois envolveu pensar no tema a ser trabalhado, criando os diálogos com a linguagem mais adequada ao público infantil, além de verificar se as figuras estavam representando o que se queriam passar de informação.

A eficácia da mensagem transmitida pelo quadrinho está na amplitude da intersecção entre as informações de texto e imagem que se reforçam mutuamente para que a mensagem tenha o entendimento esperado. Os desenhos cumprem seu papel dentro do enredo a partir do momento que permitem ao leitor visualizar a história narrada com fidelidade. ${ }^{15}$

As experiências de uso de $\mathrm{HQ}$ com a finalidade de ensinar, necessitam de cuidados que vão desde a concepção da história, passando pelos conceitos abordados, até a escolha da forma como os personagens se comunicam com o leitor e entre si, pois, por se tratar de um documento informativo, os quadrinhos voltados para a promoção da saúde, se mal concebidos, podem trazer problemas graves às propostas da mesma. ${ }^{7}$
Nesse sentido, com objetivo de disseminar conhecimentos sobre as doenças transmitidas por alimentos, autores brasileiros construíram uma $\mathrm{HQ}$ buscando retratar o cotidiano da clientela infantil, valorizando seu conhecimento e motivando-os a aproximar-se da leitura. Outro estudo que abordou o tema "álcool com adolescentes" em uma comunidade quilombola, utilizando o método criativo sensível, construiu e validou uma $\mathrm{HQ}$ que também aproximou o senso comum do conhecimento científico. ${ }^{16,17}$

Nesse contexto, a HQD pode ser utilizada para que as evidências científicas sobre a história natural da doença (COVID-19) e as suas medidas de prevenção sejam traduzidas em linguagem adequada ao contexto das crianças, jovens e adultos.

A ideia de usar uma História em Quadrinhos Digital também já foi utilizada por outros autores com o objetivo de construir um Diário de Bordo para descrição e narrativa de atividades de um subprojeto intitulado "OuSADAs". A inovação do subprojeto encontra-se na utilização de uma linguagem apropriada às histórias em quadrinhos como suporte para abordagens cuja metodologia é ativa. E, embora o potencial da HQD tenha sido constatado na experiência no ensino superior, ainda é muito incipiente a sua utilização nesse nível de ensino. ${ }^{15}$

Este é um estudo de reflexão, que tem como objetivo descrever a experiência da elaboração e utilização de uma HQ acerca do brinquedo terapêutico instrucional (BTI) sobre punção venosa, que mostrou que a $\mathrm{HQ}$ é uma tecnologia em saúde que contribui para a assistência de enfermagem pediátrica. ${ }^{18}$

Diante da construção de um HQD que traz à tona uma grande personagem histórica, como Florence Nightingale, no ano em que se comemora o seu bicentenário de nascimento, e também recorda a Teoria Ambientalista de sua autoria em um momento tão atual, não deixa de ser uma homenagem e a oportunidade de abordar as medidas de prevenção no combate ao novo coronavírus de forma lúdica e dialógica assim que for possível a retomada às atividades presenciais com os alunos e a clientela. Destaca-se que o presente estudo descreve uma experiência piloto, que tem como limitação a não validação da HQD. Espera-se a possibilidade de aplicação da presente HQD na comunidade escolar e na rotina dos profissionais de saúde das Estratégias de Saúde da Família, como uma tecnologia em saúde viável para auxiliar na compreensão do combate ao novo coronavírus.

\section{CONCLUSÃO E IMPLICAÇÕES PARA A PRÁTICA}

A história em quadrinhos produzida pelos alunos e docentes foi construída com o objetivo de transmitir informação de forma simples e lúdica sobre as medidas de prevenção de infecções por coronavírus (COVID-19), a fim de alcançar as crianças e seus familiares. As experiências de pensar o roteiro, a maneira como abordar o conteúdo, a escolha da forma dos personagens e a apresentação final em formato digital são desafios para alunos extensionistas. 
Destaca-se a oportunidade da descoberta de novos recursos pedagógicos e produção de material tecnológico em tempos de pandemia da COVID-19 e de distanciamento social. Em razão da história em quadrinhos ser direcionada principalmente para crianças e jovens, considera-se esta uma ferramenta de comunicação de massa capaz de auxiliar na difusão do conhecimento e importância da Enfermagem, ao tratar de um personagem importante desta profissão na abordagem de temas de educação em saúde.

A contribuição deste estudo está em responder as demandas de ações educativas onde o tema "higiene" está associado à prevenção da COVID-19 de uma forma lúdica para crianças, jovens e adultos.

\section{CONTRIBUIÇÕES DOS AUTORES}

Desenho da proposta do relato de experiência. Lucas Eduardo Mello Barboza. Isaque Souza da Silveira. Paula Carvalho Leite. Marialda Moreira Christoffel.

Coleta de informações para a produção da história em quadrinhos. Lucas Eduardo Mello Barboza. Isaque Souza da Silveira. Paula Carvalho Leite. Marialda Moreira Christoffel.

Análise de dados e interpretação dos resultados. Lucas Eduardo Mello Barboza. Isaque Souza da Silveira. Paula Carvalho Leite. Marialda Moreira Christoffel. Ana Leticia Monteiro Gomes. Tania Vignuda de Souza. Gláucia Cristina Lima da Silva.

Redação e revisão crítica do manuscrito. Lucas Eduardo Mello Barboza. Isaque Souza da Silveira. Paula Carvalho Leite. Marialda Moreira Christoffel. Ana Leticia Monteiro Gomes. Tania Vignuda de Souza. Gláucia Cristina Lima da Silva.

Aprovação da versão final do artigo. Lucas Eduardo Mello Barboza. Isaque Souza da Silveira. Paula Carvalho Leite. Marialda Moreira Christoffel. Ana Leticia Monteiro Gomes. Tania Vignuda de Souza. Gláucia Cristina Lima da Silva.

Responsabilidade por todos os aspectos do conteúdo e a integridade do artigo publicado. Lucas Eduardo Mello Barboza Isaque Souza da Silveira. Paula Carvalho Leite. Marialda Moreira Christoffel. Ana Leticia Monteiro Gomes. Tania Vignuda de Souza. Gláucia Cristina Lima da Silva.

\section{EDITOR ASSOCIADO}

Candida Caniçali Primo

\section{REFERENCIAS}

1. Ministério da Saúde (BR). OMS define 2020 como ano internacional dos profissionais de enfermagem e obstetrícia [Internet]. 2020 [citado 2020 Maio 4]. Disponível em: http://bvsms.saude.gov.br/component/ content/article? $\mathrm{id}=3119$
2. Nightingale F. Notas sobre enfermagem: um guia para os cuidadores na actualidade. Loures: Lusociência; 2011.

3. Peres MAA. Escola de Enfermagem Anna Nery da Universidade Federal do Rio de Janeiro: 90 anos de sua criação. Esc Anna Nery. 2013;17(1):7-9. http://dx.doi.org/10.1590/S1414-81452013000100001.

4. Bedford J, Enria D, Giesecke J, Heymann DL, Ihekweazu C, Kobinger $\mathrm{G}$ et al. COVID-19: towards controlling of a pandemic. Lancet. 2020 mar;395(10229):1015-8. http://dx.doi.org/10.1016/S0140-6736(20)306735. PMid:32197103.

5. Medeiros ABA, Enders BC, Lira ALBC. The Florence Nightingale's environmental theory: a critical analysis. Esc Anna Nery. 2015;9(3):51824. http://dx.doi.org/10.5935/1414-8145.20150069.

6. Xavier GKRS. Histórias em quadrinhos: panorama histórico, características e verbo-visualidade. Dandarina Rev Eletron [Internet]. 2018; [citado 2020 maio 23];10(2):1-20. Disponível em: http://www.ufjf.br/darandina/ files/2018/01/Artigo-Glayci-Xavier.pdf

7. Prado CC, Sousa Jr CES, Pires ML. Comic strips: a tool for education and health promotion. Rev Eletron Comun Inf Inov Saúde [Internet]. 2017; [citado 2020 jul 10];11(2):1-12. Disponível em: https://www.arca.fiocruz.br/ bitstream/icict/19698/2/ve_Prado_Carolina_Concei\%C3\%A7\%C3\%A3o_ etal_2017.pdf

8. Gazetta SMM, Sobrinho VC. História em quadrinhos como gênero textual e o desenvolvimento da leitura e da escrita. Acta Cient Ciênc Hum [Internet]. 2014; [citado 2020 maio 4];2(17):23-37. Disponível em: https://revistas.unasp.edu.br/acch/article/view/25

9. G1. Maurício de Sousa diz que Cascão também está tomando banho contra Covid-19. Gazeta Digital [Internet], Alagoas, 31 mar 2020.

10. Cicuto CAT, Chagas SS, Santos CS. A student-centered approach to teach chemistry: investigating the use of comic books as a didactic resource. Vivências. 2019 Jul;15(29):199-208. http://dx.doi.org/10.31512/ vivencias.v15i29.84.

11. Al-Samarraie $\mathrm{H}$, Hurmuzan $\mathrm{S}$. A review of brainstorming techniques in higher education. Think Skills Creat. 2018 mar;7:78-91. http://dx.doi. org/10.1016/j.tsc.2017.12.002.

12. Silva O. Grandes enfermeiras Florence Nightingale e Anna Nery [Internet] 2016; [citado 2020 jul 30]. Disponível em: http://www.guiadosquadrinhos. com/edicao/grandes-enfermeiras-florence-nightingale-e-anna-nery/ gr194510/147365

13. Silva O. A história de Florence Nightingale em Cordel [Internet] 2016 [citado 2020 jul 30]. Disponível em: https://www.youtube.com/ watch? $v=$ SRirMHB6wjA

14. DBpedia. About: Storyboard [Internet]. 2020 [citado 2020 maio 4] Disponível em: http://dbpedia.org/page/Storyboard

15. Rocha HSC, Vasconcelos AJ, Rodrigues RMSC. A journal as digita comic: the HQD OuSADAs and its innovative contribution to the teaching and learning of ABPj. Rev Thema [Internet]. 2019; [citado 2020 jul 10];16(2):346-60. Disponível em: http://periodicos.ifsul.edu.br/index. php/thema/article/view/1094

16. Sezefredo TS, Murata FHA, Peresi JTM, Paschoal VDA, Pedro HSP, Nard SMT. Comic strips to teach about prevention against foodborne disease. Arq Ciênc Saúde. 2016 abr;23(2):81-6. http://dx.doi.org/10.17696/23183691.23.2.2016.232.

17. Partelli AN, Cabral IE. Stories about alcohol drinking in a quilombola community: participatory methodology for creatingvalidating a comic book by adolescents. Texto Contexto Enferm [Internet]. 2017; [citado 2020 jul 10];26(4):e2820017. Disponível em: https://www.scielo.br/scielo. php?lng=pt\&pid=S0104-07072017000400323\&script=sci_arttext\&tlng=pt

18. Rolim KMC, Pinheiro CW, Magalhães FJ, Frota MA, Mendonça FAC, Fernandes HIVM. Comic books: technology in health for the humanization of care delivery to hospitalized children. Rev Enf Ref. 2017; serIV(14):69-78. http://dx.doi.org/10.12707/RIV17028.

\footnotetext{
a Este artigo é um recorte dos resultados do projeto de extensão intitulado "Segurança do recém-nascido e criança em diferentes contextos" em parceria com o projeto de extensão "Foi sem querer": os acidentes e a violência no contexto da criança e do adolescente, e, a educação em saúde com abordagem lúdica cadastrado na PR5/UFRJ.
} 